OPEN ACCESS

Edited by:

Miao Yan,

Central South University, China

Reviewed by:

Masatomo Miura,

Akita University Hospital, Japan

Takero Shindo,

Kyoto University Hospital, Japan

*Correspondence:

Yufei Feng

fenyufei@126.com

Lin Huang

huanglin@pkuph.edu.cn

Specialty section:

This article was submitted to Pharmacology of Anti-Cancer Drugs,

a section of the journal

Frontiers in Pharmacology

Received: 19 October 2021 Accepted: 11 November 2021

Published: 06 December 2021

Citation:

He S, Bian J, Shao Q, Zhang Y, Hao X, Luo $X$, Feng $Y$ and Huang $L$ (2021)

Therapeutic Drug Monitoring and Individualized Medicine of Dasatinib: Focus on Clinical Pharmacokinetics and Pharmacodynamics.

Front. Pharmacol. 12:797881.

doi: 10.3389/fphar.2021.797881

\section{Therapeutic Drug Monitoring and Individualized Medicine of Dasatinib: Focus on Clinical Pharmacokinetics and Pharmacodynamics}

\author{
Shiyu He ${ }^{1,2}$, Jialu Bian ${ }^{1,2}$, Qianhang Shao ${ }^{1}$, Ying Zhang ${ }^{1}$, Xu Hao ${ }^{1}$, Xingxian Luo ${ }^{3}$, \\ Yufei Feng ${ }^{1 *}$ and Lin Huang ${ }^{1 *}$
}

${ }^{1}$ Department of Pharmacy, People's Hospital of Peking University, Beijing, China, ${ }^{2}$ Department of Pharmacy Administration and Clinical Pharmacy, School of Pharmaceutical Sciences, Peking University, Beijing, China, ${ }^{3}$ School of Pharmaceutical Sciences, Tsinghua University, Beijing, China

Dasatinib is an oral second-generation tyrosine kinase inhibitor known to be used widely in Philadelphia chromosome-positive $\left(\mathrm{Ph}^{+}\right)$chronic myeloid leukemia $(\mathrm{CML})$ and $\mathrm{Ph}^{+}$acute lymphoblastic leukemia (ALL). Notably, although a high pharmacokinetic variability in patients and an increased risk of pleural effusion are attendant, fixed dosing remains standard practice. Retrospective studies have suggested that dasatinib exposure may be associated with treatment response (efficacy/safety). Therapeutic drug monitoring (TDM) is gradually becoming a practical tool to achieve the goal of individualized medicine for patients receiving targeted drugs. With the help of TDM, these patients who maintain response while have minimum adverse events may achieve long-term survival. This review summaries current knowledge of the clinical pharmacokinetics variation, exposureresponse relationships and analytical method for individualized dosing of dasatinib, in particular with respect to therapeutic drug monitoring. In addition, it highlights the emerging insights into several controversial issues in TDM of dasatinib, with the aim of presenting up-to-date evidence for clinical decision-making and insights for future studies.

Keywords: dasatinib, pharmacokinetics, exposure-response relationships, analytical method, therapeutic drug monitoring, individualized medicine

\section{INTRODUCTION}

Dasatinib is an oral second-generation dual Src-Abll kinase inhibitor indicated for the treatment of adults and children with Philadelphia chromosome-positive $\left(\mathrm{Ph}^{+}\right)$chronic myeloid leukemia (CML) and $\mathrm{Ph}^{+}$acute lymphoblastic leukemia (ALL) with resistance or intolerance to prior therapy including imatinib, and has become the first-line treatment for CML (Lindauer and Hochhaus, 2018). Dasatinib is 325 times as potent as imatinib in inhibiting unmutated BCR-ABL kinase in vitro, and has inhibitory activity against the majority of imatinib-resistant BCR-ABL mutants (Lombardo et al., 2004). Besides, dasatinib has activity in multiple other kinases, including c-KIT, PDGFR $\beta$, and ephrin receptor kinases (Lindauer and Hochhaus, 2018).

Dasatinib has showed an association between exposure and response. As pharmacokinetic (PK) exposure of dasatinib varies highly among patients, some patients may be exposed to the risk of therapeutically relevant toxicity due to high exposure, while others may suffer from suboptimal efficacy resulted from low exposure (Verheijen et al., 2017). Additionally, dose reduction has become 
a target for further treatment in some patients with CML having achieved cytogenetic and hematological responses, which can not only reduce the incidence and severity of toxicities, but also lighten the financial burden on patients. However, after the responses have been achieved, we do not have a clear indicator to guide reduction for achieving maximum benefits under minimum dose. Although dasatinib has showed satisfactory efficacy, it still has problems worried us.

Therapeutic drug monitoring (TDM) is an effective tool aimed at optimizing a patient's drug regimen based on biological fluids concentrations of the drug. Several pieces of evidence suggest potential benefits of TDM for the treatment of cancer with tyrosine kinase inhibitors (TKIs). For the treatment dilemma that dasatinib is currently facing, TDM is likely to be an effective assistant strategy to contribute to the solution of problems in clinical practice. Nevertheless, no consensus has been reached on the TDM of dasatinib, including whether it is carried out routinely, monitoring indicators, target ranges and feasibility, etc. The focus of this review is to discuss the problems above in terms of factors affecting exposure of dasatinib, exposureresponse relationships for dasatinib in previous studies, as well as analytical method.

\section{PHARMACOKINETICS VARIABILITY}

Very high interpatient variability of dasatinib exposure was observed on maximum plasma drug concentration $\left(\mathrm{C}_{\max }\right)$, $70-80 \%$, and on area under the plasma concentration-time curve (AUC), 40-54\% (Wang et al., 2013; Ishida et al., 2016; Chandani et al., 2017). Moreover, one study suggested that the variability in exposure of dasatinib was greater within subjects than between subjects (Dai et al., 2008). Many factors that lead to the high variability of dasatinib by influencing the PK process of dasatinib need to be considered.

\subsection{Absorption}

Dasatinib is rapidly absorbed following oral administration with time to $\mathrm{C}_{\max }\left(\mathrm{T}_{\max }\right)$ ranging from 0.5 to $6 \mathrm{~h}$ (European Medicines Agency, 2006). With the emergence of more studies, $\mathrm{T}_{\max }$ values observed among subjects ranged from 0.28 to $6.3 \mathrm{~h}$ (Horinkova et al., 2019). The oral bioavailability was rather low in preclinical studies with values ranging from 45 to $51 \%$ (Luo et al., 2006a), whereas other studies showed bioavailability from 14 to $34 \%$ (Kamath et al., 2008b). Although a high-fat meal increases the mean AUC of dasatinib by $14 \%$ after a single dose of $100 \mathrm{mg}$ (Bristol-Myers Squibb, 2017), the change is not clinically significant.

The most important factor impacting dasatinib absorption is gastric $\mathrm{pH}$. Dasatinib $\left(\mathrm{pK}_{\mathrm{a}}=3.1,6.8\right.$, and 10.8) is a weak base drug and dissolves better in an acidic environment and precipitates in the small intestine (Tsume et al., 2015) (BCS/BDDCS II) (Budha et al., 2012). An extremely low AUC (54.1 ng.h/mL) and $\mathrm{C}_{\max }$ $(8.3 \mathrm{ng} / \mathrm{ml})$ were reported in a patient with a history of total gastrectomy surgery, showing that the influence of gastric $\mathrm{pH}$ on reduced absorption of dasatinib through total gastrectomy surgery for the first time (Iwamoto et al., 2019). An in vivo study had shown that the elevated gastric $\mathrm{pH}$ range of 4.0-6.0 would significantly reduce the solubility of dasatinib (Tsume et al., 2015). Due to the $\mathrm{pH}$-dependent solubility, all coadministration agents regulating gastric $\mathrm{pH}$ may have a great impact on the oral bioavailability of dasatinib, including proton pump inhibitors (PPIs), $\mathrm{H}_{2}$-receptor antagonists $\left(\mathrm{H}_{2} \mathrm{RAs}\right)$, antacids, pentagastrin and betaine $\mathrm{HCl}$ (Table $\mathbf{1}$ ).

PPIs (omeprazole, lansoprazole, rabeprazole and esomeprazole) which cancer patients often take for palliation of the gastroesophageal reflux, dyspepsia, and gastritis, have the effect of decreasing dasatinib exposure, which has been demonstrated in several studies. In study of Budha et al., after 4 days administration of omeprazole $(40 \mathrm{mg} / \mathrm{d})$, dasatinib $(100 \mathrm{mg} / \mathrm{d})$ was administered concomitantly with omeprazole on the next day. The $\mathrm{C}_{\max }$, AUC from time zero extrapolated to infinite time $\left(\mathrm{AUC}_{\text {inf }}\right)$ and relative bioavailability $\left(\mathrm{F}_{\mathrm{R}}\right)$ of dasatinib in healthy subjects were reduced by 42,43 and $\sim 40 \%$, respectively (Wang et al., 2008; Budha et al., 2012). In another study, 6 healthy subjects who began with a pretreatment of $20 \mathrm{mg}$ rabeprazole twice daily for 3 days, were given a morning dose on the morning of the fourth study day before $100 \mathrm{mg}$ dasatinib, and significant reductions in dasatinib $\mathrm{C}_{\max }$ and $\mathrm{AUC}_{\text {inf }}$ of 78 and $84 \%$ were observed (Yago et al., 2014). One case report has also indicated that after esomeprazole discontinuation for 4 days, $\mathrm{C}_{\max }$ and the estimated $\mathrm{AUC}_{0-6.5}$ increased from 23.1 to $52.0 \mathrm{ng} / \mathrm{ml}$ and from 89.6 to $130.6 \mathrm{ng} \cdot \mathrm{h} / \mathrm{mL}$, respectively (Pape et al., 2016).

$\mathrm{H}_{2} \mathrm{RAs}$ significantly reduce dasatinib exposure both in animals and human. In the preclinical study, when the rats were given $3.4 \mathrm{mg}$ of dasatinib (equal to $50 \mathrm{mg}$ in human) along with famotidine $(10 \mathrm{mg} / \mathrm{kg})$ injected $2 \mathrm{~h}$ prior to dasatinib dosing, the $\mathrm{AUC}_{\text {inf }}$ of dasatinib approximately declined 4.5-fold compared with the control group (Lubach et al., 2013). In healthy subjects, a dramatic decrease in $\mathrm{C}_{\max }$ and $\mathrm{AUC}_{0-12}$ of dasatinib of 63 and $61 \%$, respectively, was observed even though they were taking famotidine $10 \mathrm{~h}$ earlier than dasatinib (Eley et al., 2009). Same trend was also noticed in a patient with $\mathrm{Ph}^{+}$ ALL (Matsuoka et al., 2012). On the contrary, famotidine taken $2 \mathrm{~h}$ post dasatinib had no effect on the $\mathrm{PK}$ of dasatinib, suggesting that administration of famotidine $2 \mathrm{~h}$ following dasatinib mitigated the interaction between these two drugs (Eley et al., 2009).

Similarly, when healthy subjects received $30 \mathrm{ml}$ of aluminum hydroxide/magnesium hydroxide-containing antacid (Maalox) co-administered with dasatinib, the $\mathrm{AUC}_{0-12}$ and $\mathrm{C}_{\max }$ of dasatinib were decreased drastically by 55 and $58 \%$, respectively. Whereas the antacid Maalox, taken $2 \mathrm{~h}$ before dasatinib, showed no significant change (Eley et al., 2009).

Interestingly, pentagastrin, which is well-known to stimulate acid secretion in mammals, was found to reduce exposure of dasatinib in rats. A reasonable explanation may be that dasatinib is probably fully dissolved in the stomach because of the high solubility at low $\mathrm{pH}$ (below $\sim$ ), indicating that as the drug passes through the intestinal tract $(\mathrm{pH}$ increases to 5-7), systemic absorption of dasatinib decreases owing to rapid supersaturation in the gut and possible precipitation. In this study, the gastric juice of fasted rats was highly acidic, with a 
TABLE 1 | Effect of gastric acid pH modulators on the oral absorption of dasatinib.

\begin{tabular}{|c|c|c|c|c|c|c|c|}
\hline \multirow{2}{*}{$\begin{array}{l}\text { Dasatinib } \\
\text { (dose regimen) }\end{array}$} & \multicolumn{2}{|c|}{ Gastric acid pH modulator (dose) } & \multirow[t]{2}{*}{ Subject (N) } & \multicolumn{2}{|c|}{ Change } & \multirow[t]{2}{*}{ Comment } & \multirow[t]{2}{*}{ References } \\
\hline & & & & AUC & $\mathbf{C}_{\max }$ & & \\
\hline 100 mg, QD & $\begin{array}{l}\text { Day 1: dasatinib; Days } \\
\text { dasatinib and omeprazc }\end{array}$ & $\begin{array}{l}\text { 5: omeprazole (40 mg); Day 6: } \\
\text { (40 mg) }\end{array}$ & $\begin{array}{l}\text { Healthy } \\
\text { subjects } \\
(\mathrm{N}=13)\end{array}$ & $\downarrow 43 \%$ & $\downarrow 42 \%$ & $\begin{array}{l}A \cup C_{\text {inf }} \\
C_{\max }\end{array}$ & $\begin{array}{l}\text { Clinicaltrials.gov, (2009); } \\
\text { Budha et al., (2012) }\end{array}$ \\
\hline \multirow[t]{4}{*}{50 mg, Q12H } & \multirow{2}{*}{\multicolumn{2}{|c|}{$\begin{array}{l}\text { Famotidine }(40 \mathrm{mg}) 2 \mathrm{~h} \text { after the evening dose of } \\
\text { dasatinib } \\
\text { Famotidine }(40 \mathrm{mg}) 10 \mathrm{~h} \text { before the morning dose of } \\
\text { dasatinib }\end{array}$}} & $\begin{array}{l}\text { Healthy } \\
\text { subjects }\end{array}$ & \multicolumn{2}{|c|}{ No significant change } & $\begin{array}{l}\mathrm{AUC}_{0-12} \\
\mathrm{C}_{\max }\end{array}$ & Eley et al. (2009) \\
\hline & & & $\begin{array}{l}(\mathrm{N}=21 \\
\text { crossover }\end{array}$ & $\downarrow 61 \%$ & $\downarrow 63 \%$ & & \\
\hline & \multirow{2}{*}{\multicolumn{2}{|c|}{$\begin{array}{l}\text { Maalox }^{\mathrm{a}}(30 \mathrm{ml}) 2 \mathrm{~h} \text { prior to dasatinib } \\
\text { Maalox }^{\mathrm{a}}(30 \mathrm{ml}) \text { co-administered with dasatinib }\end{array}$}} & study) & $\uparrow 5 \%^{b}$ & $\uparrow 26 \%$ & & \\
\hline & & & & $\downarrow 55 \%$ & $\downarrow 58 \%$ & & \\
\hline 20-140 mg, Q12H & \multicolumn{2}{|c|}{$\begin{array}{l}\text { Lansoprazole }(30 \mathrm{mg}) \text { or famotidine }(20-40 \mathrm{mg} / \mathrm{d}) \text { or } \\
\text { nizatidine }(300 \mathrm{mg} / \mathrm{d})\end{array}$} & $\begin{array}{l}\mathrm{CML} \text { or } \mathrm{Ph}^{+} \\
\mathrm{ALL} \\
(\mathrm{N}=12)\end{array}$ & $\begin{array}{l}\text { Median: } \downarrow \\
58 \%^{\mathrm{b}}\end{array}$ & $\begin{array}{l}\text { Median: } \downarrow \\
72 \%{ }^{\mathrm{b}}\end{array}$ & $\begin{array}{l}\mathrm{AUC}_{0-4} \mathrm{SS} ; \\
\mathrm{C}_{2} \mathrm{SS}\end{array}$ & Takahashi et al. (2012a) \\
\hline 70 mg, BID & \multicolumn{2}{|l|}{ Famotidine (20 mg) } & $\begin{array}{l}\mathrm{Ph}^{+} \mathrm{ALL}(\mathrm{N} \\
=1)\end{array}$ & $\downarrow 72 \%{ }^{b}$ & / & $\mathrm{AUC}_{0-12}$ & Matsuoka et al. (2012) \\
\hline \multirow{4}{*}{$\begin{array}{l}3.4 \pm 0.1 \mathrm{mg}, \mathrm{QD} \\
\text { (based on a } 50 \mathrm{mg} \\
\text { human dose) } \\
100 \mathrm{mg}, \mathrm{QD}\end{array}$} & \multirow{2}{*}{\multicolumn{2}{|c|}{$\begin{array}{l}\text { Famotidine }(10 \mathrm{mg} / \mathrm{kg} \text {, iv) } 2 \mathrm{~h} \text { prior to dasatinib } \\
\text { Pentagastrin }(0.25 \mathrm{mg} / \mathrm{kg} \text {, ih) } 2 \mathrm{~h} \text { prior to dasatinib }\end{array}$}} & Rats $(N=5)$ & $\downarrow 78 \%$ & $\downarrow 82 \%$ & $A \cup C_{\text {inf }}$ & \multirow[t]{2}{*}{ Lubach et al. (2013) } \\
\hline & & & Rats $(N=5)$ & $\downarrow 29 \%$ & $\downarrow 43 \%$ & $\mathrm{C}_{\max }$ & \\
\hline & \multirow[t]{2}{*}{$\begin{array}{l}\text { Pretreatment: } \\
\text { Rabeprazole ( } 20 \text { mg, } \\
\text { BID) for } 3 \text { days }\end{array}$} & $\begin{array}{l}\text { Rabeprazole }(20 \mathrm{mg}) \text {, gastric } \\
\mathrm{pH} \geq 4 \text { for at least } 15 \mathrm{~min} \\
\text { before dasatinib }\end{array}$ & $\begin{array}{l}\text { Healthy } \\
\text { subjects } \\
(\mathrm{N}=12\end{array}$ & $\downarrow 78 \%$ & $\downarrow 92 \%$ & $\begin{array}{l}A \cup C_{\text {inf }} \\
\mathrm{C}_{\max }\end{array}$ & Yago et al. (2014) \\
\hline & & $\begin{array}{l}\text { Betaine } \mathrm{HCl}(1,500 \mathrm{mg}) \\
5 \text { min prior to dasatinib }\end{array}$ & $\begin{array}{l}\text { crossover } \\
\text { study) }\end{array}$ & $\uparrow 5 \%$ & $\uparrow 21 \%$ & & \\
\hline 50 mg, QD & \multicolumn{2}{|l|}{ Esomeprazole (40 mg) } & $\begin{array}{l}\mathrm{Ph}^{+} \mathrm{ALL}(\mathrm{N} \\
=1)\end{array}$ & $\downarrow 32 \%$ & $\downarrow 56 \%$ & $\begin{array}{c}\mathrm{AUC}_{0-6.5} \\
\mathrm{C}_{\max }\end{array}$ & Pape et al. (2016) \\
\hline
\end{tabular}

QD, once daily; BID, twice daily; Q12H, every $12 h ; N$, number of subjects; iv, intravenous injection; ih, hypodermic injection; ss, steady state.

${ }^{a}$ Maalox, Aluminum hydroxide/magnesium hydroxide-containing antacid.

${ }^{b}$ Calculated from the data in the reference; /, unmentioned in the reference.

$\mathrm{pH}$ around 2, which is close to the value of the pentagastrin pretreatment group (Lubach et al., 2013). That means patients had better not take dasatinib with a prolonged fast, although food has no effect on the absorption of dasatinib.

In order to mitigate the interaction between PPIs and dasatinib, two studies reported the effects of betaine $\mathrm{HCl}$ and acidic beverages. Patients pretreated with rabeprazole received betaine $\mathrm{HCl}(1,500 \mathrm{mg}) 5 \mathrm{~min}$ pre-dasatinib and it was able to restore dasatinib $\mathrm{AUC}_{\text {inf }}$ and $\mathrm{C}_{\max }$ to 1.05, and 1.21-fold of the control treatment with dasatinib alone. That means that the reduced exposure to dasatinib induced by rabeprazole can be reversed through coadministration with betaine $\mathrm{HCl}$ (Yago et al., 2014). Furthermore, it was found that the effect of concomitant strong acid-reducing agents on ketoconazole, posaconazole, and erlotinib absorption may be offset by coadministration of acidic beverages such as glutamic acid, dilute hydrochloric acid, or carbonated beverages (e.g., cola). Since both dasatinib and these drugs require an acidic environment for optimal absorption, thus, Knoebel et al. suggest that coadministration of acidic beverages such as cola with dasatinib may be a rational option for patients who require potent acid-reducing agents, especially for PPIs (Knoebel and Larson, 2018).

\subsection{Distribution}

Approximately $96 \%$ of dasatinib (93\% of its active metabolite) is bound to human plasma proteins (mainly to albumin) in vitro (Bristol-Myers Squibb, 2017). And the apparent volume of distribution is $2505 \mathrm{~L}$ (Bristol-Myers Squibb, 2017), demonstrating that dasatinib is well distributed into tissues. As we learned, drugs with moderate to high affinity for the same binding sites can have an effect on free drug serum concentrations by competing protein binding sites. For instance, aspirin, displaced valproate from protein binding sites and the free fraction of valproate increased significantly (Orr et al., 1982). Regrettably, no study on the protein binding of dasatinib was found. In addition, there was a negative correlation between the amount of albumin and valproate concentration (Lai et al., 2020). Additional attention should be paid to patients with low albumin levels due to complicated cirrhosis or hypoproteinemia on account of the high binding of dasatinib to plasma proteins.

The cellular uptake of dasatinib is not dependent on drug transporters. The intracellular uptake and retention (IUR) of dasatinib was linear over the range of drug concentrations tested at 4 and $37^{\circ} \mathrm{C}$ temperatures, suggesting that the cellular uptake is mainly a passive process (Giannoudis et al., 2008; Hiwase et al., 2008). Accordingly, dasatinib uptake is not dependent on hOCT1 (hOCT2 and hOCT3, too (Kamath et al., 2008a)) in contrast to imatinib, even if dasatinib is a substrate for hOCT1 (Giannoudis et al., 2008).

The cellular efflux of dasatinib is partially regulated by drug transporters, which has been confirmed by studies both in vivo and in vitro. The effects of several efflux proteins belonging to the ATP-binding cassette transporter family on dasatinib diffusion have been reported in multiple studies, including ABCB1 (MDR1/P-gp), ABCG2 (BCRP) and ABCC6 (MRP6). It had been shown that dasatinib was a substrate for both P-gp and BCRP by cell models (Giannoudis et al., 2008; Hiwase et al., 2008) as well as directly measuring intracellular dasatinib levels (Chen 
et al., 2009; Hegedus et al., 2009). Overexpression of ABCB1 or ABCG2 protein reduced dasatinib IUR, resulting in an increase in the $\mathrm{IC}_{50}$ of dasatinib, which could be modulated with inhibitors (Hiwase et al., 2008; Chen et al., 2009). Likewise, a study conducted in BCR-ABL1 ${ }^{+}$cell lines indicated that inhibition of ABCC6 reduced dasatinib efflux, leading to a significant decrease in $\mathrm{IC}_{50}$ of dasatinib (Eadie et al., 2018).

The central nervous system (CNS) delivery of dasatinib is predominantly subject to the limitations of P-gp and BCRP. In vivo, there was no difference in brain accumulation of dasatinib between $A b c g 2^{-/-}$mice and wild-type (WT) mice, but it was 3.6fold and 13.2-fold increase in $A b c b 1 a / 1 b^{-/-}$and $A b c b 1 a / 1 b ; A b c g 2^{-/-}$ mice, respectively (Lagas et al., 2009), which was confirmed in study by Chen et al. (2009) These results show that P-gp likely exerts a leading role in limiting CNS delivery of dasatinib, whereas BCRP alone shows no such effect on CNS transport of dasatinib. Notably, similar results were reported for imatinib and lapatinib. It suggests that there appears to be a "synergistic" activity of P-gp and BCRP, with the highest efflux activity exhibited by the combination of these two transporters (Bihorel et al., 2007; Chen et al., 2009; Lagas et al., 2009; Polli et al., 2009). The CNS concentration in patients was rarely examined and mostly was undetectable, even if the samples were collected in the absorptive phase (Porkka et al., 2008). In 7 patients with CML or $\mathrm{Ph}^{+}$ALL (including adult and pediatric), the brain-to-plasma concentration $(\mathrm{B} / \mathrm{P})$ ratio was detected $(0.01,0.03,0.03,0.04,0.05,0.08$, and 0.28) (Porkka et al., 2008; Zhou et al., 2013). And the B/P ratios of $\mathrm{AUC}_{0-24}$ in 2 pediatric patients with diffuse intrinsic pontine glioma were 0.028 and 0.016 (Broniscer et al., 2013). The finding that P-gp and BCRP have a combined effect on CNS delivery of drug may have significant implications for the treatment of CNS leukemia.

PPIs are substrates and inhibitors of P-gp (Pauli-Magnus et al., 2001). High concentrations of pantoprazole and esomeprazole ( 1 and $2 \mathrm{mM}$ ) resulted in a significant increase of dasatinib IUR in ABCB1 overexpressing cells (Hiwase et al., 2010), which was probably due to the fact that PPIs inhibited the function of P-gp to pump the dasatinib out of the target cells. However, this concentrations at clinically relevant doses is much lower than that of 1 and $2 \mathrm{mM}$ and thus does not achieve the effect of P-gp inhibition. There are other $\mathrm{P}$-gp inhibitors which also have no in vitro and in vivo data, including cyclosporine, itraconazole, calcium antagonists, antiarrhythmic drugs and macrolides antibiotics. More care still should be taken if co-administered with these drugs.

\subsection{Metabolism}

Dasatinib is metabolized in humans, primarily by CYP3A4, and flavin-containing monooxygenase 3 (FMO-3) and uridine diphosphate-glucuronosyltransferase (UGT) enzymes are also involved in the formation of dasatinib metabolites (BristolMyers Squibb, 2017). Routes of metabolism include hydroxylation, N-dealkylation, N-oxidation, alcohol oxidation and direct glucuronide or sulphate conjugation (Horinkova et al., 2019). There are five phase I circulating metabolites: M4, M5, M6, M20 and M24, among which M20 and M24 represent 45 and $25 \%$ of the $\mathrm{AUC}_{0-24}$ of dasatinib, respectively. The primary active metabolite, M4
(N-dealkylated) whose antiproliferative activity in vitro is similar to that of dasatinib represents only $5 \%$ of dasatinib AUC(Leveque et al., 2020).

The coadministration of CYP3A4 inhibitors or inducers lead to varying degrees of fluctuation in dasatinib plasma concentrations. The mean $\mathrm{C}_{\max }$ and AUC of dasatinib increased by 4-fold and 5fold, respectively, when used in combination with ketoconazole (strong CYP3A4 inhibitor) (Bristol-Myers Squibb, 2017). Similarly, other moderate or strong CYP3A4 inhibitors used frequently in patients with CML may have the same effect, such as, aprepitan, grapefruit juice, macrolides antibiotics (clarithromycin and erythromycin), azole antifungal agents (itraconazole, voriconazole, and posaconazole) and so on. In opposite, the coadministration of rifampin (strong CYP3A4 inducer) decreased the mean $\mathrm{C}_{\max }$ and AUC of dasatinib by 81 and $82 \%$, respectively (Bristol-Myers Squibb, 2017). Other CYP3A4 inducers include antiepileptic drugs, dexamethasone and herbal preparations such as St John's wort (known as hypericum perforatum in China) and ginseng (Leveque et al., 2020).

The data from European public assessment reports (EPARs) show a high degree of absorption of dasatinib with the fraction of the dose absorbed $\left(\mathrm{f}_{\mathrm{abs}}\right)$ of at least $70 \%$. However, due to the low absolute bioavailability (34\%), a considerable amount of first-pass metabolism can be predictably expected. So if CYP3A4 has a $50 \%$ or greater contribution to the overall clearance of dasatinib, then a phenotype analysis might be essential for dose adjustment to enable individualized medicine (Mikus and Isabelle Foerster, 2017).

\subsection{Excretion}

Elimination is primarily via the feces. Besides, the bile also plays a role. Following a single radiolabeled dose of oral dasatinib, $4 \%$ of the administered radioactivity was recovered in the urine and $85 \%$ in the feces within 10 days, and unchanged dasatinib was in the minority. The mean terminal half-life of dasatinib is $3-5 \mathrm{~h}$ (Bristol-Myers Squibb, 2017).

The gut microbiome has been recognized as the second human genome. So, it's not surprising that large interpatient variability of the gut ecosystem has been found. Additional data has become available showing that except liver, the gut microbiome can also directly influence an individual's response to a specific drug by enzymatically transforming the drug's structure and altering its bioavailability, bioactivity or toxicity (Doestzada et al., 2018; Weersma et al., 2020). As the majority of dasatinib is excreted out of body through feces, it is worthy of further investigation for a complex interaction of dasatinib with the gut microbiome.

\subsection{Pharmacogenetics}

The pharmacogenetics of dasatinib are rarely reported. Although to date we have not found any evidence of a relationship between CYP3A4 gene polymorphisms and dasatinib PK, the effects of CYP3A4 gene polymorphisms and its regulation and expression on PK of drugs have been extensively investigated. The $C Y P 3 A 4^{\star} 1 G$ allele with high frequency in Asians was suggested to decrease CYP3A activity and fentanyl consumption (Wei et al., 2010). Additionally, in clinic observation of kidney transplantation, CYP $3 A 4^{*} 22$ carriers 
required less Tacrolimus dose to achieve the target exposure compared with $C Y P 3 A 4^{\star} 1{ }^{\star} 1$ carriers (Yu et al., 2018).

The 3 most relevant $A B C B 1$ gene polymorphisms are: $1236 \mathrm{C}>$ $\mathrm{T}, 2677 \mathrm{G}>\mathrm{T} / \mathrm{A}$, and $3435 \mathrm{C}>\mathrm{T}$. One study reported $A B C B 1 \mathrm{TTT}$ haplotype $(1236 \mathrm{~T}, 2677 \mathrm{~T}, 3435 \mathrm{~T})$ led to significantly lower intracellular accumulation of dasatinib (Skoglund et al., 2013). Moreover, an in vitro study reported that the ABCB1 1199A variant was associated to a higher $\mathrm{ABCB} 1$ efflux activity, particularly toward imatinib and dasatinib (Dessilly et al., 2016).

Taken together, all these results suggest that polymorphisms of metabolic enzymes and transporters may have a potential impact on dasatinib exposure in plasma and further studies with large sample size are needed to confirm this.

\subsection{Special Populations}

Age (15-86 years old), sex, and renal impairment (creatinine clearance $21.6 \mathrm{ml} / \mathrm{min}$ to $342.3 \mathrm{ml} / \mathrm{min}$ as estimated by Cockcroft Gault) have no clinically relevant effect on the PK of dasatinib, according to the prescribing information (Bristol-Myers Squibb, 2017).

\subsubsection{Pediatric Patients}

The PK of pediatric is very similar to that of adults. In pediatric patients with a dosing regimen of $60 \mathrm{mg} / \mathrm{m}^{2}$, the model simulated geometric mean (coefficient of variation, CV\%) steady-state plasma average concentrations of dasatinib were $14.7(64.6 \%)$ $\mathrm{ng} / \mathrm{mL}$ (for 2 to $<6$ years old), 16.3 (97.5\%) $\mathrm{ng} / \mathrm{mL}$ (for 6 to $<12$ years old), and 18.2 (67.7\%) ng/mL (for 12 years and older). Because of the difficulty in swallowing tablets, some prefer dispersed tablets, which have an estimated $36 \%$ lower bioavailability than intact tablets (Bristol-Myers Squibb, 2017).

\subsubsection{Patients With Hepatic Impairment}

Compared to subjects with normal liver function, patients with moderate hepatic impairment (Child-Pugh B) had decreases in mean $\mathrm{C}_{\max }$ by $47 \%$ and mean AUC by $8 \%$. Patients with severe hepatic impairment (Child-Pugh $\mathrm{C}$ ) had decreases in mean $\mathrm{C}_{\max }$ by $43 \%$ and in mean AUC by $28 \%$ compared to the subjects with normal liver function (Bristol-Myers Squibb, 2017). No dose adjustment for patients with hepatic impairment is currently recommended.

\section{EXPOSURE-RESPONSE RELATIONSHIPS}

\subsection{Exposure-Efficacy}

In preclinical studies (both in vivo and in vitro), it was suggested that the efficacy of kinase inhibition correlated with dasatinib exposure. In BCR-ABL-positive cell lines exposed to gradient concentrations of dasatinib (from 0.5 to $150 \mathrm{nM}$ ), phospho-BCR$\mathrm{ABL} /$ phospho-CrkL ( $\mathrm{p}-\mathrm{CrkL}$ ) levels were considerably diminished and apoptosis levels were increased with elevated concentrations of dasatinib (Copland et al., 2006; Shah et al., 2008b; Snead et al., 2009; O'hare et al., 2013), which was also shown in SRC-expressing cells (Luo et al., 2008). Results of validation in primary CML cells from CML patients were similar to those of cell lines (Shah et al., 2008b; Luo et al.,
2008; Snead et al., 2009). In a phase I study using peripheral blood mononuclear cells (PBMC) obtained from 5 dasatinibtreated CML patients, $\mathrm{p}$-CrKL decreased in a dose-dependent manner after $4 \mathrm{~h}$ of the initial dose but was largely recovered after $8 \mathrm{~h}$, coinciding with the decline in dasatinib serum levels measured in these same patients (Talpaz et al., 2006).

Besides, in tumors from mice bearing human tumor xenografts, tumoral phospho-BCR-ABL/phospho-SRC was dose-dependently inhibited (a single oral dose ranging from 1.25 to $50 \mathrm{mg} / \mathrm{kg}$ ), and directly related to the plasma concentrations of dasatinib (Luo et al., 2006b; Luo et al., 2008). Notably, two studies reported that practically undetectable p-CrkL levels (O'hare et al., 2013) or nearmaximal apoptosis levels (Snead et al., 2009) were observed when exposed to $100 \mathrm{nM}(\sim 48.8 \mathrm{ng} / \mathrm{ml})$ dasatinib. What's more, Shah et al. found that $100 \mathrm{nM}$ dasatinib exposure killed about $90 \%$ of the cells as short as $20 \mathrm{~min}$, even for imatinibresistant (except for T315I) (Shah et al., 2008b). These results suggest that transient potent inhibition $(>50 \mathrm{ng} / \mathrm{ml})$ is sufficient to commit CML cells to apoptosis.

To the best of our knowledge, few clinical studies have shown that there is some certain link between exposure and efficacy. Plasma concentration at $2 \mathrm{~h}\left(\mathrm{C}_{2}\right), \mathrm{C}_{\max }$ and $\mathrm{AUC}_{0-4}$ detected in patients with T315I were significantly lower than those without. The median $\mathrm{C}_{\max }$ in patients with $\mathrm{T} 315 \mathrm{I}$ and without were $43.8 \mathrm{ng} / \mathrm{ml}$ and $112.4 \mathrm{ng} / \mathrm{ml}$, respectively $(p=0.0242)$ (Takahashi et al., 2012b). As a consequence, a low exposure to dasatinib may be associated with the emergence of BCR-ABL mutations, including T315I. In a prospective cohort study of 10 CML patients receiving dasatinib $100 \mathrm{mg}$ once daily, analysis by Iwamoto et al. revealed that the cut-off value of dasatinib AUC and $\mathrm{C}_{\max }$ for achieving major molecular response (MMR) within 6 months were $336.1 \mathrm{ng} \cdot \mathrm{h} / \mathrm{ml}$ and $69.2 \mathrm{ng} / \mathrm{ml}$, respectively, and the accuracy ratio to predict MMR was $88.9 \%$ for the AUC, and $77.8 \%$ for the $\mathrm{C}_{\max }$ (Iwamoto et al., 2019). It is worth noting that the monitoring of AUC cannot be generalized in clinical practice because of its operational complexity, although it is the best PK parameter to characterize dasatinib exposure. Compared with AUC, $\mathrm{C}_{\max }$ is a more applicable parameter for prediction of efficacy.

The study by Wang et al. using data from $567 \mathrm{Ph}^{+} \mathrm{CML}$ subjects indicated that achieving major cytogenetic response (MCyR) was most closely related to increasing $\mathrm{wC}_{\mathrm{avg}} \mathrm{ss}$, so from the perspective of this study, the most significant predictor of $\mathrm{MCyR}$ was $\mathrm{wC}_{\mathrm{avg}}$ ss (Wang et al., 2013). Despite $\mathrm{wC}_{\mathrm{avg}} \mathrm{ss}$ suggested to predict efficacy, TDM based on $\mathrm{wC}_{\mathrm{avg}} \mathrm{ss}$ is not feasible clinically (Yu et al., 2014).

In aggregate, it is important that transient potent dasatinib concentration of $100 \mathrm{nM}$ achieves inhibition of BCR-ABL and the effect can last for several hours, that's why dasatinib is taken once daily in spite of the short half-life. In addition, although continuous low-level exposure can achieve a similar efficacy of BCR-ABL inhibition, a relatively high exposure is needed for reducing the risk of developing $\mathrm{BCR}-\mathrm{ABL}$ point mutations. Vainstein et al. found higher inhibitory potential at peak concentration (IPP), which integrated $\mathrm{IC}_{50}$, slope, and $\mathrm{C}_{\max }$, correlated with improved complete cytogenetic response 
TABLE 2 | Overview of outcomes for patients administrated different oral dose of dasatinib.

\begin{tabular}{|c|c|c|c|c|c|c|c|c|}
\hline \multirow[t]{2}{*}{ Study } & \multirow[t]{2}{*}{ Dose } & \multirow[t]{2}{*}{ Patient (N) } & \multicolumn{5}{|c|}{ Efficacy, \% } & \multirow{2}{*}{$\begin{array}{c}\text { Safety, } \% \\
\begin{array}{c}\text { Pleural effusion } \\
\text { (all grades) }\end{array}\end{array}$} \\
\hline & & & OHR & CHR & MaHR & CCyR & MCyR & \\
\hline Cortes et al. (2007) & 70 mg, BID & CML-BC (N = 116) & 47 & 26 & 33 & 33 & 38 & 23 \\
\hline Guilhot et al. (2007) & 70 mg, BID & CML-AP (N = 107) & 81 & 39 & 64 & 24 & 33 & 23 \\
\hline Hochhaus et al. (2007) & 70 mg, BID & CML-CP (N = 186) & / & 90 & / & / & 52 & 19 \\
\hline Kantarjian et al. (2007) & 70 mg, BID & CML-CP $(\mathrm{N}=101)$ & / & 93 & / & 40 & 52 & 17 \\
\hline \multirow[t]{4}{*}{ Shah et al. (2010) } & $100 \mathrm{mg}, \mathrm{QD}$ & CML-CP (N = 167) & / & 92 & 37 & 50 & 63 & 14 \\
\hline & 50 mg, BID & CML-CP $(\mathrm{N}=168)$ & / & 92 & 38 & 50 & 61 & 23 \\
\hline & $140 \mathrm{mg}, \mathrm{QD}$ & CML-CP (N = 167) & / & 87 & 38 & 50 & 63 & 25 \\
\hline & 70 mg, BID & CML-CP (N = 168) & / & 88 & 38 & 54 & 61 & 23 \\
\hline
\end{tabular}

I, unmentioned in the reference.

OHR, overall hematologic response; CHR, complete hematologic response; MaHR, major hematologic response; CCyR, complete cytogenetic response; MCyR, major cytogenetic response; $Q D$, once daily; $B I D$, twice daily; $B C$, blast crisis; $C P$, chronic-phase; $A P$, accelerated-phase.

(CCyR) rates in CML patients treated with dasatinib (Vainstein et al., 2013), which confirmed the importance of $C_{\max }$ laterally. A study has proved that the $\mathrm{C}_{2}$ concentration, not concentration at $1 \mathrm{~h}\left(\mathrm{C}_{1}\right)$ or $4 \mathrm{~h}\left(\mathrm{C}_{4}\right)$, had a higher correlation with the measured AUC $_{0-4}$ of dasatinib using $34 \mathrm{PK}$ profiles $(r=0.9419, p<0.0001)$ (Takahashi et al., 2012a). The monitoring of $C_{2}$ concentration is easily achieved clinically to predict whether an enough $\mathrm{C}_{\max }$ will be obtained.

On the whole, the monitoring of dasatinib $\mathrm{C}_{\max } / \mathrm{C}_{2}$ level does make sense. It is generally accepted that a relatively high $\mathrm{C}_{\max }$ level should be maintained to ensure the clinical efficacy and to reduce the risk of dasatinib resistance. Based on current limited evidence, it is recommended to maintain $\mathrm{C}_{2}$ concentration at least $\geq 50 \mathrm{ng} / \mathrm{ml}$.

Additionally, dasatinib showed the special capacity to induce immunomodulation. The present in vitro studies indicated that dasatinib dose-dependently inhibited the proliferation and function of $\mathrm{CD}^{+} \mathrm{CD} 25^{+}$regulatory $\mathrm{T}$ cells (Tregs) (Fei et al., 2009), meanwhile it enhanced the expansion of large granular lymphocytes [LGLs, mono- or oligoclonal $\mathrm{CD} 8^{+} \mathrm{T}$ cells, $\gamma \delta \mathrm{T}$ cells, and natural killer (NK) cells] (Uchiyama et al., 2013). This effect was also confirmed using a collection of 37 leukemia patients that the blood counts closely mirrored dasatinib plasma concentrations (Mustjoki et al., 2013). Importantly, most of the dasatinib discontinuation trials showed that increased LGLs levels and reduced immune suppressive Treg levels in dasatinib treatment interrupted patients were linked to better prognosis and treatment-free remission (TFR) successes (Hughes and Yong, 2017; Climent and Plana, 2019). Therefore, we reasonably speculate that the exposure of dasatinib is closely related to TFR. However, no studies currently have been conducted to determine whether dasatinib exposure levels correlate with successful TFR. But it is highly worthy of investigation and discussion, and we expect that such research will emerge in the future.

\subsection{Exposure-Safety}

Reviewing data from several clinical studies, it was found that pleural effusion (PE), an adverse event, was intimately associated with dasatinib treatment, and was the primary reason for discontinuation. In DASISION study, fluid retention (all grades) occurred more frequently with imatinib than with dasatinib (42 vs. 19\%), yet it's a remarkable fact that PE was reported only in the dasatinib group: 26 patients (10\%) (Kantarjian et al., 2010). Subsequently, it was also identified that the incidence of $\mathrm{PE}$ was related to the dasatinib dose regimens, with the lowest of the $100 \mathrm{mg}$ once daily regimen (Shah et al., 2008a; Shah et al., 2016) (Table 2).

A phase II study (OPTIM) reported that after CML patients with a trough plasma concentration $\left(\mathrm{C}_{0}\right)$ value $\geq 3 \mathrm{nmol} / \mathrm{L}$ (about $1.5 \mathrm{ng} / \mathrm{ml}$ ) were randomly assigned between the continuation of dasatinib $100 \mathrm{mg} / \mathrm{d}$ (control arm: $n=42$ ) and a dose reduction strategy (TDM arm: $n=38$ ), the TDM arm had a significantly lower cumulative incidence of $\mathrm{PE}(12$ vs. 39\%) and discontinuation rates ( 21 vs. $36 \%$ ) compared to the control arm by 36 months. It was encouraging that molecular responses evaluated during 3 years were found to be similar in both arms (Rousselot et al., 2021). In study by Mizuta et al. (2018), CML patients administered dasatinib once daily at a dose of $100 \mathrm{mg}(n=27)$ or $50 \mathrm{mg}(n=5)$ had a median $\mathrm{C}_{0}$ of dasatinib of $1.4 \mathrm{ng} / \mathrm{ml}$, with no significance in $\mathrm{PE}$ rate between high $\mathrm{C}_{0}$ group $(\geq 1.4 \mathrm{ng} / \mathrm{ml})$ and low $\mathrm{C}_{0}$ group $(<1.4 \mathrm{ng} / \mathrm{ml})(31 \mathrm{vs.} 19 \%)$. Nonetheless, after adjusting for dasatinib dose $(\mathrm{g})$ and body weight $(\mathrm{kg})\left(\mathrm{C}_{0} / \mathrm{D} / \mathrm{W}\right)$, higher median $\mathrm{C}_{0}$ was correlated with the incidence of the dasatinib interruption/reduction in treatment. These results suggest that dose optimization by $\mathrm{C}_{0}$ assessment using TDM, a valuable "PE prediction tool" (Rousselot et al., 2021), reduces the risk of exposure to PE while ensuring the efficacy.

Wang et al. (2013) also found that patients with $100 \mathrm{mg}$ once daily schedule had the lowest $\mathrm{PE}$ rate $(11 \%)$ and steady-state $\mathrm{C}_{0}$ of dasatinib $(2.61 \mathrm{ng} / \mathrm{ml})$. And the $\mathrm{C}_{0}$ was identified as the most significant predictor of $\mathrm{PE}$ in the Cox proportional hazards model (hazard increased 1.22-fold for every $1 \mathrm{ng} / \mathrm{ml}$ increase in $\mathrm{C}_{0}$ ). Based on Wang et al.'s study (Wang et al., 2008), Yu et al. (2014) defined a dose interruption rate of about $50 \%$ as a non-acceptable cut-off, then the $\mathrm{C}_{0}$ should not exceed $2.5 \mathrm{ng} / \mathrm{ml}$ in chronic phase CML patients. However, this cut-off value should be interpreted with caution in the clinic, as it is derived from a mixed dosing regimen $(n=567)$. What's more, the analysis by Verheijen et al. (2017) 
TABLE 3 | Overview of LC-MS/MS analytical methods of dasatinib in human plasma in recent 5 years.

\begin{tabular}{|c|c|c|c|c|c|c|}
\hline References & Analtye & Analytical column & $\begin{array}{l}\text { Internal } \\
\text { standard }\end{array}$ & $\begin{array}{c}\text { Calibration } \\
\text { range, } \\
\text { ng/mL }\end{array}$ & $\begin{array}{l}\text { LLOQ, } \\
\mathrm{ng} / \mathrm{mL}\end{array}$ & Extraction \\
\hline Huynh et al. (2017) & Dasatinib, other $13 \mathrm{TKIs}$ & $\begin{array}{l}\text { Acquity UPLC BEH C18 column } \\
(2.1 \mathrm{~mm} \times 50 \mathrm{~mm} ; 1.9 \mu \mathrm{m})\end{array}$ & ${ }^{2} \mathrm{H}_{8}$-dasatinib & $1-500$ & 0.75 & PPT \\
\hline Wojnicz et al. (2017) & Dasatinib, imatinib, nilotinib & $\begin{array}{l}\text { Poroshell } 120 \text { EC-C18 column }(2.1 \mathrm{~mm} \\
\times 75 \mathrm{~mm}, 2.7 \mu \mathrm{m})\end{array}$ & $D_{8}$-dasatinib & $0.75-400$ & 0.75 & SPE \\
\hline Zeng et al. (2017) & Dasatinib, imatinib, nilotinib & $\begin{array}{l}\text { Xtimate Phenyl column }(2.1 \mathrm{~mm} \times \\
150 \mathrm{~mm}, 3 \mu \mathrm{m})\end{array}$ & / & $2-490$ & 2 & LLE \\
\hline Maher et al. (2018) & Dasatinib & $\begin{array}{l}\text { Acquity UPLC BEH C18 column } \\
(1.0 \mathrm{~mm} \times 100 \mathrm{~mm}, 1.7 \mu \mathrm{m})\end{array}$ & Erlotinib & $1-500$ & 1 & SPE \\
\hline Merienne et al. (2018) & $\begin{array}{l}\text { Dasatinib, other } 16 \text { TKIs and } 2 \\
\text { metabolites }\end{array}$ & $\begin{array}{l}\text { CORTECS UPLC C18 column }(2.1 \times \\
50 \mathrm{~mm}, 1.6 \mu \mathrm{m})\end{array}$ & ${ }^{13} \mathrm{C}_{6}$-dasatinib & $0.1-200$ & 0.1 & SPE \\
\hline Ezzeldin et al. (2020) & Dasatinib, other 6 TKIs & $\begin{array}{l}\text { Acquity UPLC BEH C18 column } \\
(2.1 \mathrm{~mm} \times 100 \mathrm{~mm}, 1.7 \mu \mathrm{m})\end{array}$ & Quizartinib & $5-1000$ & 5 & PPT \\
\hline Koller et al. (2020) & Dasatinib, other $10 \mathrm{TKIs}$ & $\begin{array}{l}\text { Poroshell } 120 \text { EC-C18 column }(2.1 \mathrm{~mm} \\
\times 75 \mathrm{~mm}, 2.7 \mu \mathrm{m})\end{array}$ & $\mathrm{D}_{8}$-dasatinib & $0.38-400$ & 0.38 & PPT; SPE \\
\hline Mukai et al. (2020) & $\begin{array}{l}\text { Dasatinib, other } 4 \text { TKIs and } 3 \text { active } \\
\text { metabolites }\end{array}$ & $\begin{array}{l}\text { L-column3 C18 }(2.1 \mathrm{~mm} \times \\
50 \mathrm{~mm}, 3 \mu \mathrm{m})\end{array}$ & $D_{8}$-dasatinib & $0.5-150$ & 0.5 & SLE \\
\hline Hirasawa et al. (2021) & Dasatinib, other 4 TKls & $\begin{array}{l}\text { Triart C18 MetalFree column }(2.1 \mathrm{~mm} \times \\
50 \mathrm{~mm}, 3 \mu \mathrm{m})\end{array}$ & ${ }^{2} \mathrm{H}_{8}$-dasatinib & $0.1-200$ & 0.1 & PPT \\
\hline Llopis et al. (2021) & $\begin{array}{l}\text { Dasatinib, other } 8 \text { TKls, } 2 \text { active } \\
\text { metabolites and } 2 \text { AAs }\end{array}$ & $\begin{array}{l}\text { Acquity UPLC T3 HSS C18 column (2.1 } \\
\times 100 \mathrm{~mm}, 1.8 \mu \mathrm{m})\end{array}$ & ${ }^{2} \mathrm{H}_{8}$-dasatinib & $1-500$ & 1 & PPT \\
\hline $\begin{array}{l}\text { Sumimoto et al. } \\
\text { (2021) }\end{array}$ & $\begin{array}{l}\text { Dasatinib, other } 4 \text { TKIs and } 2 \text { active } \\
\text { metabolites }\end{array}$ & $\begin{array}{l}\text { Acquity BEH C18 column }(2.1 \mathrm{~mm} \times \\
50 \mathrm{~mm}, 1.7 \mu \mathrm{m})\end{array}$ & $D_{8}$-dasatinib & $0.2-200$ & 0.2 & SPE \\
\hline $\begin{array}{l}\text { Verougstraete et al. } \\
\text { (2021) }\end{array}$ & Dasatinib, other 7 TKls & $\begin{array}{l}\text { Acquity UPLC BEH C18 column } \\
(2.1 \mathrm{~mm} \times 100 \mathrm{~mm}, 1.7 \mu \mathrm{m})\end{array}$ & $D_{8}$-dasatinib & $0.5-450$ & 0.5 & PPT \\
\hline
\end{tabular}

I, unmentioned in the reference.

PPT, protein precipitation; SPE, solid-phase extraction; LLE, liquid-liquid extraction; SLE, supported liquid extraction method using an ISOLUTE SLE+ column; LC-MS/MS, liquid chromatography/electrospray ionization-tandem mass spectrometry; AAs, antiandrogen drugs.

indicated that across all kinase inhibitors, the target exposure fitted $81.7 \%$ of the population exposure and supported the argument that in the absence of a definitive TDM target, the geometric mean $\mathrm{C}_{0}$ of dasatinib $[2.61 \mathrm{ng} / \mathrm{ml}$ for $100 \mathrm{mg}$ once daily, $n=146$ (Wang et al., 2013)], representing the CML population average, could be an alternative. There was an additional viewpoint from Mirua et al. who suggested the $\mathrm{C}_{0}$ cut-off value of $4.33 \mathrm{ng} / \mathrm{ml}$ (median) from the regression model studied by Wang et al. (2013) be determined as the minimum toxic concentration (MTC) to avoid PE (Miura and Takahashi, 2019). On balance, the above recommendations on the target range for dasatinib $\mathrm{C}_{0}$ are derived from single data source (all based on Wang et al.' study), and as such need to be supported by additional evidence.

Age was a major risk factor for PE, which was confirmed in several studies (Wang et al., 2013; Mizuta et al., 2018; Rousselot et al., 2021). And it was found that this effect was driven by PK parameters (Wang et al., 2013). Patients with high median age had a higher level of $\mathrm{C}_{0}$, and so did a higher incidence of PE. As a result, the therapeutic window of elderly patients may be narrower relative to younger patients, and these patients may need more intensive monitoring.

All things considered, the relationship between $\mathrm{C}_{0}$ of dasatinib and the occurrence of $\mathrm{PE}$ in patients has been basically established, i. e., maintaining a relatively low level of $\mathrm{C}_{0}$ can reduce the risk of PE. Meanwhile, the threshold of dasatinib $\mathrm{C}_{0}$ from some experts' suggestions is concentrated at $2-5 \mathrm{ng} / \mathrm{ml}$, despite lack of hard evidence to support it.
Consequently, it is necessary to monitor $\mathrm{C}_{0}$ of dasatinib, but the target range needs to be further explored and confirmed.

\section{ANALYTICAL METHOD}

Because of the low steady-state blood concentration of dasatinib, the currently preferred analytical method for measuring concentrations of dasatinib is liquid chromatography-tandem mass spectrometry (LC-MS/MS), which has a high sensitivity for quantifying unchanged dasatinib in biological fluids. Table 3 shows studies on the LC-MS/MS analytical method of dasatinib published in recent 5 years (Table 3). Recently, some studies have reported other methods used for dasatinib, such as sequential spectrophotometric-based univariate methods (Abdelhameed et al., 2021). Most studies determined dasatinib levels with a lower limit of quantification (LLOQ) of $1 \mathrm{ng} / \mathrm{ml}$ (Couchman et al., 2012; Furlong et al., 2012; Birch et al., 2013), while the method of Bouchet et al. (2011) determined dasatinib levels with a lower LLOQ of $0.1 \mathrm{ng} / \mathrm{mL}$. A study found that about $4.7 \%$ of the available dasatinib concentration measurements (contained 4044 measurements) were below the LLOQ of $1.0 \mathrm{ng} / \mathrm{ml}$ (Wang et al., 2013; Miura and Takahashi, 2016), suggesting that lower LLOQ of less than $1.0 \mathrm{ng} / \mathrm{ml}$ was a necessity.

Currently, the monitoring of dasatinib uses plasma samples, which contain both free and bound fractions. However, only free drug in equilibrium with cells can exert pharmacological effects. 
Simultaneously, pharmacologically active free fraction may undergo significant changes due to variations in the concentration, conformation, and/or other physicochemical properties of plasma proteins (Haouala et al., 2013). Hence, free dasatinib concentration should be in consideration because of its high protein binding rate (Widmer et al., 2014). There was a study measured free and total imatinib concentrations and predicted imatinib free concentrations by an established model based on total concentrations and plasma proteins measurements (Haouala et al., 2013).

Plasma samples are collected in tubes using heparin or EDTA as anticoagulant by immediate centrifugation. Different sample preparation methods, such as protein precipitation (PPT) (Haouala et al., 2009; Huynh et al., 2017), solid-phase extraction (SPE) (Bouchet et al., 2011; Furlong et al., 2012; Wojnicz et al., 2017; Koller et al., 2020) and liquid-liquid extraction (LLE) (Couchman et al., 2012; Birch et al., 2013), have been used for TKIs. PPT, however, is at most risk of causing ion suppression in electrospray ionization (ESI), since it does not remove all endogenous compounds that interfere with ESI-LC-MS/MS analysis (Koller et al., 2020). In particular, samples will be diluted by the addition of protein precipitator, resulting in a lower concentration of the drug to be measured. Therefore, it is not suitable for samples with low concentration like $\mathrm{C}_{0}$ of dasatinib. LLE is characterized by clean extraction, of which multiple extraction steps are required to improve the recovery of analytes. SPE is less time-consuming and requires less solvent volume (Koller et al., 2020), which is a more costly method compared with LLE (Zeng et al., 2017). Moreover, Mukai et al. employed a supported liquid extraction method using an ISOLUTE SLE+ column which was more convenient compared to SPE (Mukai et al., 2020). Another proper alternative to SPE is thin-film solid-phase microextraction (TF-SPME) whose distinctive characteristics are high sensitivity, large extraction capacity, and minimum requisite sample pre-treatment (Khodayari et al., 2021).

\section{CONCLUSION AND PROSPECT}

The findings presented in this review demonstrate that TDM of dasatinib is essential and feasible, and the clinical benefits of dasatinib TDM in individualized medicine have also been initially shown. Based on the evidence currently available, scholars suggest that maintain a relatively high level of $\mathrm{C}_{2}$ or $\mathrm{C}_{\max }$ to obtain sufficient efficacy and reduce the risk of BCR-ABL

\section{REFERENCES}

Abdelhameed, A. S., Hassan, E. S., Attwa, M. W., Al-Shakliah, N. S., Alanazi, A. M., and Alrabiah, H. (2021). Simple and Efficient Spectroscopic-Based Univariate Sequential Methods for Simultaneous Quantitative Analysis of Vandetanib, Dasatinib, and Sorafenib in Pharmaceutical Preparations and Biological Fluids. Spectrochim Acta A. Mol. Biomol. Spectrosc. 260, 119987. doi:10.1016/j.saa.2021.119987

Bihorel, S., Camenisch, G., Lemaire, M., and Scherrmann, J. M. (2007). Influence of Breast Cancer Resistance Protein (Abcg2) and P-Glycoprotein (Abcbla) on the Transport of Imatinib Mesylate (Gleevec) across the Mouse Blood-Brain Barrier. J. Neurochem. 102, 1749-1757. doi:10.1111/j.1471-4159.2007.04808.x mutations, and a relatively low level of $\mathrm{C}_{0}$ to reduce the risk of exposure to PE. Moreover, age is a factor with more attention and elderly patients may need regular monitoring compared with young patients.

At present, there is a real need to identify the range of the monitoring target and high-quality controlled studies need to be performed to confirm its appropriateness, especially for $\mathrm{C}_{0}$. Accordingly, with the progressing of the research, a classification refinement of dasatinib TDM is likely needed, such as diseases, ages, races and so on. Following the launch of targeted drugs with safety and efficacy, more and more patients are achieving responses, accompanied by increasing demands for dose reduction. Extending the existing knowledge with additional studies in the field of individualized medicine will open up the era of guiding reduction by TDM and implementing it into clinical practice in the foreseeable future to improve patients' quality of life. Additionally, to facilitate clinical application, there is an inevitable need to advance technologies for feasible and accurate monitoring of drug concentrations. For example, the determination of free concentration or the free concentration modelled predicted can more accurately reflect the exposure of pharmacologically active free fraction. Overall, the strategy of TDM will help overcome difficulties of dasatinib in treatment and bring further survival benefit and a better quality of life for patients in the future.

\section{AUTHOR CONTRIBUTIONS}

$\mathrm{LH}$ and YF contributed to conception and design of the study. $\mathrm{SH}$, JB and XH helped with the literature search and organization. QS and $\mathrm{YZ}$ contributed to data extraction. $\mathrm{SH}$ wrote the manuscript. $\mathrm{XL}$ drew the tables. All authors contributed to manuscript revision. All authors read and approved the final manuscript.

\section{FUNDING}

This work was supported by the Beijing Municipal Natural Science Foundation (grant number 7192218).

\section{ACKNOWLEDGMENTS}

We would like to thank Prof. Qian Jiang for valuable clinical comments on this review.

Birch, M., Morgan, P. E., Handley, S., Ho, A., Ireland, R., and Flanagan, R. J. (2013). Simple Methodology for the Therapeutic Drug Monitoring of the Tyrosine Kinase Inhibitors Dasatinib and Imatinib. Biomed. Chromatogr. 27, 335-342. doi: $10.1002 /$ bmc. 2796

Bouchet, S., Chauzit, E., Ducint, D., Castaing, N., Canal-Raffin, M., Moore, N., et al. (2011). Simultaneous Determination of Nine Tyrosine Kinase Inhibitors by $96-$ well Solid-phase Extraction and Ultra Performance LC/MS-MS. Clin. Chim. Acta 412, 1060-1067. doi:10.1016/j.cca.2011.02.023

Bristol-Myers Squibb (2017). Sprycel: Full Prescribing Information. E. coli. Available at: https://packageinserts.bms.com/pi/pi_sprycel.pdf (Accessed September 29, 2021).

Broniscer, A., Baker, S. D., Wetmore, C., Pai Panandiker, A. S., Huang, J., Davidoff, A. M., et al. (2013). Phase I Trial, Pharmacokinetics, and Pharmacodynamics of 
Vandetanib and Dasatinib in Children with Newly Diagnosed Diffuse Intrinsic Pontine Glioma. Clin. Cancer Res. 19, 3050-3058. doi:10.1158/1078-0432.CCR13-0306

Budha, N. R., Frymoyer, A., Smelick, G. S., Jin, J. Y., Yago, M. R., Dresser, M. J., et al. (2012). Drug Absorption Interactions between Oral Targeted Anticancer Agents and PPIs: Is pH-dependent Solubility the Achilles Heel of Targeted Therapy? Clin. Pharmacol. Ther. 92, 203-213. doi:10.1038/clpt.2012.73

Chandani, R., He, J., and Trabelsi, F. (2017). "Atypical Pharmacokinetic Profiles Observed with Dasatinib Reference Listed Drug Product in Bioequivalence Studies," in Conference presentation (San Diego, CA, United States: AAPS Annual Meeting). Available at: http://www.BioPharmaServices.com.

Chen, Y., Agarwal, S., Shaik, N. M., Chen, C., Yang, Z., and Elmquist, W. F. (2009). P-glycoprotein and Breast Cancer Resistance Protein Influence Brain Distribution of Dasatinib. J. Pharmacol. Exp. Ther. 330, 956-963. doi:10.1124/jpet.109.154781

Climent, N., and Plana, M. (2019). Immunomodulatory Activity of Tyrosine Kinase Inhibitors to Elicit Cytotoxicity against Cancer and Viral Infection. Front. Pharmacol. 10, 1232. doi:10.3389/fphar.2019.01232

Clinicaltrials.gov (2009). The Effect of Omeprazole on the Pharmacokinetics of Dasatinib (BMS-354825) in Healthy Subjects. E. coli. Available at: https://clinicaltrials.gov/ct2/ show/results/NCT00655746?term $=$ NCT00655746\&draw $=2 \&$ rank $=1$ (Accessed September 29, 2021).

Copland, M., Hamilton, A., Elrick, L. J., Baird, J. W., Allan, E. K., Jordanides, N., et al. (2006). Dasatinib (BMS-354825) Targets an Earlier Progenitor Population Than Imatinib in Primary CML but Does Not Eliminate the Quiescent Fraction. Blood 107, 4532-4539. doi:10.1182/blood-2005-07-2947

Cortes, J., Rousselot, P., Kim, D. W., Ritchie, E., Hamerschlak, N., Coutre, S., et al. (2007). Dasatinib Induces Complete Hematologic and Cytogenetic Responses in Patients with Imatinib-Resistant or -intolerant Chronic Myeloid Leukemia in Blast Crisis. Blood 109, 3207-3213. doi:10.1182/blood-2006-09-046888

Couchman, L., Birch, M., Ireland, R., Corrigan, A., Wickramasinghe, S., Josephs, D., et al. (2012). An Automated Method for the Measurement of a Range of Tyrosine Kinase Inhibitors in Human Plasma or Serum Using Turbulent Flow Liquid Chromatography-Tandem Mass Spectrometry. Anal. Bioanal. Chem. 403, 1685-1695. doi:10.1007/s00216-012-5970-2

Dai, G., Pfister, M., Blackwood-Chirchir, A., and Roy, A. (2008). Importance of Characterizing Determinants of Variability in Exposure: Application to Dasatinib in Subjects with Chronic Myeloid Leukemia. J. Clin. Pharmacol. 48, 1254-1269. doi:10.1177/0091270008320604

Dessilly, G., Elens, L., Panin, N., Karmani, L., Demoulin, J. B., and Haufroid, V. (2016). ABCB1 1199G >A Polymorphism (Rs2229109) Affects the Transport of Imatinib, Nilotinib and Dasatinib. Pharmacogenomics 17, 883-890. doi:10.2217/pgs-2016-0012

Doestzada, M., Vila, A. V., Zhernakova, A., Koonen, D. P. Y., Weersma, R. K., Touw, D. J., et al. (2018). Pharmacomicrobiomics: a Novel Route towards Personalized Medicine? Protein Cell 9, 432-445. doi:10.1007/s13238-0180547-2

Eadie, L. N., Dang, P., Goyne, J. M., Hughes, T. P., and White, D. L. (2018). ABCC6 Plays a Significant Role in the Transport of Nilotinib and Dasatinib, and Contributes to TKI Resistance In Vitro, in Both Cell Lines and Primary Patient Mononuclear Cells. PLoS One 13, e0192180. doi:10.1371/journal.pone.0192180

Eley, T., Luo, F. R., Agrawal, S., Sanil, A., Manning, J., Li, T., et al. (2009). Phase I Study of the Effect of Gastric Acid pH Modulators on the Bioavailability of Oral Dasatinib in Healthy Subjects. J. Clin. Pharmacol. 49, 700-709. doi:10.1177/ 0091270009333854

European Medicines Agency (2006). Sprycel: EPAR - Scientific Discussion. E. coli. Available at: http://www.ema.europa.eu (Accessed September 29, 2021).

Ezzeldin, E., Iqbal, M., Herqash, R. N., and Elnahhas, T. (2020). Simultaneous Quantitative Determination of Seven Novel Tyrosine Kinase Inhibitors in Plasma by a Validated UPLC-MS/MS Method and its Application to Human Microsomal Metabolic Stability Study. J. Chromatogr. B Analyt Technol. Biomed. Life Sci. 1136, 121851. doi:10.1016/j.jchromb.2019.121851

Fei, F., Yu, Y., Schmitt, A., Rojewski, M. T., Chen, B., Götz, M., et al. (2009). Dasatinib Inhibits the Proliferation and Function of CD4+CD25+ Regulatory T Cells. Br. J. Haematol. 144, 195-205. doi:10.1111/j.1365-2141.2008.07433.x

Furlong, M. T., Agrawal, S., Hawthorne, D., Lago, M., Unger, S., Krueger, L., et al. (2012). A Validated LC-MS/MS Assay for the Simultaneous Determination of the Anti-leukemic Agent Dasatinib and Two Pharmacologically Active
Metabolites in Human Plasma: Application to a Clinical Pharmacokinetic Study. J. Pharm. Biomed. Anal. 58, 130-135. doi:10.1016/j.jpba.2011.09.008

Giannoudis, A., Davies, A., Lucas, C. M., Harris, R. J., Pirmohamed, M., and Clark, R. E. (2008). Effective Dasatinib Uptake May Occur without Human Organic Cation Transporter 1 (hOCT1): Implications for the Treatment of ImatinibResistant Chronic Myeloid Leukemia. Blood 112, 3348-3354. doi:10.1182/ blood-2007-10-116236

Guilhot, F., Apperley, J., Kim, D. W., Bullorsky, E. O., Baccarani, M., Roboz, G. J., et al. (2007). Dasatinib Induces Significant Hematologic and Cytogenetic Responses in Patients with Imatinib-Resistant or -intolerant Chronic Myeloid Leukemia in Accelerated Phase. Blood 109, 4143-4150. doi:10.1182/ blood-2006-09-046839

Haouala, A., Widmer, N., Guidi, M., Montemurro, M., Leyvraz, S., Buclin, T., et al. (2013). Prediction of Free Imatinib Concentrations Based on Total Plasma Concentrations in Patients with Gastrointestinal Stromal Tumours. Br. J. Clin. Pharmacol. 75, 1007-1018. doi:10.1111/j.1365-2125.2012.04422.x

Haouala, A., Zanolari, B., Rochat, B., Montemurro, M., Zaman, K., Duchosal, M. A., et al. (2009). Therapeutic Drug Monitoring of the New Targeted Anticancer Agents Imatinib, Nilotinib, Dasatinib, Sunitinib, Sorafenib and Lapatinib by LC Tandem Mass Spectrometry. J. Chromatogr. B Analyt Technol. Biomed. Life Sci. 877, 1982-1996. doi:10.1016/j.jchromb.2009.04.045

Hegedus, C., Ozvegy-Laczka, C., Apáti, A., Magócsi, M., Német, K., Orfi, L., et al. (2009). Interaction of Nilotinib, Dasatinib and Bosutinib with ABCB1 and ABCG2: Implications for Altered Anti-cancer Effects and Pharmacological Properties. Br. J. Pharmacol. 158, 1153-1164. doi:10.1111/j.14765381.2009.00383.x

Hirasawa, T., Kikuchi, M., Shigeta, K., Takasaki, S., Sato, Y., Sato, T., et al. (2021). High-throughput Liquid Chromatography/electrospray Ionization-Tandem Mass Spectrometry Method Using In-Source Collision-Induced Dissociation for Simultaneous Quantification of Imatinib, Dasatinib, Bosutinib, Nilotinib, and Ibrutinib in Human Plasma. Biomed. Chromatogr. 35, e5124. doi:10.1002/ bmc. 5124

Hiwase, D. K., Saunders, V., Hewett, D., Frede, A., Zrim, S., Dang, P., et al. (2008). Dasatinib Cellular Uptake and Efflux in Chronic Myeloid Leukemia Cells: Therapeutic Implications. Clin. Cancer Res. 14, 3881-3888. doi:10.1158/10780432.CCR-07-5095

Hiwase, D. K., White, D., Zrim, S., Saunders, V., Melo, J. V., and Hughes, T. P. (2010). Nilotinib-mediated Inhibition of ABCB1 Increases Intracellular Concentration of Dasatinib in CML Cells: Implications for Combination TKI Therapy. Leukemia 24, 658-660. doi:10.1038/leu.2009.242

Hochhaus, A., Kantarjian, H. M., Baccarani, M., Lipton, J. H., Apperley, J. F., Druker, B. J., et al. (2007). Dasatinib Induces Notable Hematologic and Cytogenetic Responses in Chronic-phase Chronic Myeloid Leukemia after Failure of Imatinib Therapy. Blood 109, 2303-2309. doi:10.1182/blood-200609-047266

Horinkova, J., Sima, M., and Slanar, O. (2019). Pharmacokinetics of Dasatinib. Prague Med. Rep. 120, 52-63. doi:10.14712/23362936.2019.10

Hughes, A., and Yong, A. S. M. (2017). Immune Effector Recovery in Chronic Myeloid Leukemia and Treatment-free Remission. Front. Immunol. 8, 469. doi:10.3389/fimmu.2017.00469

Huynh, H. H., Pressiat, C., Sauvageon, H., Madelaine, I., Maslanka, P., Lebbé, C., et al. (2017). Development and Validation of a Simultaneous Quantification Method of 14 Tyrosine Kinase Inhibitors in Human Plasma Using LC-MS/MS. Ther. Drug Monit. 39, 43-54. doi:10.1097/FTD.0000000000000357

Ishida, Y., Murai, K., Yamaguchi, K., Miyagishima, T., Shindo, M., Ogawa, K., et al. (2016). Pharmacokinetics and Pharmacodynamics of Dasatinib in the Chronic Phase of Newly Diagnosed Chronic Myeloid Leukemia. Eur. J. Clin. Pharmacol. 72, 185-193. doi:10.1007/s00228-015-1968-y

Iwamoto, T., Monma, F., Ohishi, K., Umino, A., Suzuki, K., Oka, K., et al. (2019). Evaluation of Medication Adherence and Pharmacokinetics of Dasatinib for Earlier Molecular Response in Japanese Patients with Newly Diagnosed Chronic Myeloid Leukemia: A Pilot Study. Ther. Drug Monit. 41, 575-581. doi:10.1097/FTD.0000000000000639

Kamath, A. V., Wang, J., Lee, F. Y., and Marathe, P. H. (2008a). Preclinical Pharmacokinetics and In Vitro Metabolism of Dasatinib (BMS-354825): a Potent Oral Multi-Targeted Kinase Inhibitor against SRC and BCR-ABL. Cancer Chemother. Pharmacol. 61, 365-376. doi:10.1007/s00280-0070478-8 
Kamath, A. V., Wang, J., Lee, F. Y., and Marathe, P. H. (2008b). Preclinical Pharmacokinetics and In Vitro Metabolism of Dasatinib (BMS-354825): a Potent Oral Multi-Targeted Kinase Inhibitor against SRC and BCR-ABL. Cancer Chemother. Pharmacol. 61, 365-376. doi:10.1007/s00280-007-0478-8

Kantarjian, H., Pasquini, R., Hamerschlak, N., Rousselot, P., Holowiecki, J., Jootar, S., et al. (2007). Dasatinib or High-Dose Imatinib for Chronic-phase Chronic Myeloid Leukemia after Failure of First-Line Imatinib: a Randomized Phase 2 Trial. Blood 109, 5143-5150. doi:10.1182/blood-2006-11-056028

Kantarjian, H., Shah, N. P., Hochhaus, A., Cortes, J., Shah, S., Ayala, M., et al. (2010). Dasatinib versus Imatinib in Newly Diagnosed Chronic-phase Chronic Myeloid Leukemia. N. Engl. J. Med. 362, 2260-2270. doi:10.1056/ NEJMoa1002315

Khodayari, P., Jalilian, N., Ebrahimzadeh, H., and Amini, S. (2021). Trace-level Monitoring of Anti-cancer Drug Residues in Wastewater and Biological Samples by Thin-Film Solid-phase Micro-extraction Using Electrospun polyfam/Co-MOF-74 Composite Nanofibers Prior to Liquid Chromatography Analysis. J. Chromatogr. A. 1655, 462484. doi:10.1016/ j.chroma.2021.462484

Knoebel, R. W., and Larson, R. A. (2018). Pepsi ${ }^{\circledR}$ or Coke ${ }^{\circledR}$ ? Influence of Acid on Dasatinib Absorption. J. Oncol. Pharm. Pract. 24, 156-158. doi:10.1177/ 1078155217692152

Koller, D., Vaitsekhovich, V., Mba, C., Steegmann, J. L., Zubiaur, P., Abad-Santos, F., et al. (2020). Effective Quantification of 11 Tyrosine Kinase Inhibitors and Caffeine in Human Plasma by Validated LC-MS/MS Method with Potent Phospholipids Clean-Up Procedure. Application to Therapeutic Drug Monitoring. Talanta 208, 120450. doi:10.1016/j.talanta.2019.120450

Lagas, J. S., Van Waterschoot, R. A., Van Tilburg, V. A., Hillebrand, M. J., Lankheet, N., Rosing, H., et al. (2009). Brain Accumulation of Dasatinib Is Restricted by P-Glycoprotein (ABCB1) and Breast Cancer Resistance Protein (ABCG2) and Can Be Enhanced by Elacridar Treatment. Clin. Cancer Res. 15, 2344-2351. doi:10.1158/1078-0432.CCR-08-2253

Lai, Y. H., Huang, Q. Y., Liang, Y. J., Huang, X. W., Li, C. Y., and Tang, S. H. (2020). Influencing Factors of Serum Valparaiso Acid Concentration in Children with Epilepsy Based on Multivariate Linear Regression. J. Pediatr. Pharm. 26, 37-39.

Levêque, D., Becker, G., Bilger, K., and Natarajan-Amé, S. (2020). Clinical Pharmacokinetics and Pharmacodynamics of Dasatinib. Clin. Pharmacokinet. 59, 849-856. doi:10.1007/s40262-020-00872-4

Lindauer, M., and Hochhaus, A. (2018). Dasatinib. Berlin, Germany: Springer International Publishing, 29-68. doi:10.1007/978-3-319-91439-8_2

Llopis, B., Robidou, P., Tissot, N., Pinna, B., Gougis, P., Aubart, F. C., et al. (2021). Development and Clinical Validation of a Simple and Fast UPLC-ESI-MS/MS Method for Simultaneous Quantification of Nine Kinase Inhibitors and Two Antiandrogen Drugs in Human Plasma: Interest for Their Therapeutic Drug Monitoring. J. Pharm. Biomed. Anal. 197, 113968. doi:10.1016/ j.jpba.2021.113968

Lombardo, L. J., Lee, F. Y., Chen, P., Norris, D., Barrish, J. C., Behnia, K., et al. (2004). Discovery of N-(2-chloro-6-methyl- Phenyl)-2-(6-(4-(2Hydroxyethyl)- Piperazin-1-Yl)-2-Methylpyrimidin-4- Ylamino)thiazole-5Carboxamide (BMS-354825), a Dual Src/Abl Kinase Inhibitor with Potent Antitumor Activity in Preclinical Assays. J. Med. Chem. 47, 6658-6661. doi:10.1021/jm049486a

Lubach, J. W., Chen, J. Z., Hau, J., Imperio, J., Coraggio, M., Liu, L., et al. (2013). Investigation of the Rat Model for Preclinical Evaluation of $\mathrm{pH}$-dependent Oral Absorption in Humans. Mol. Pharm. 10, 3997-4004. doi:10.1021/ mp400283j

Luo, F. R., Barrett, Y. C., Yang, Z., Camuso, A., Mcglinchey, K., Wen, M. L., et al. (2008). Identification and Validation of Phospho-SRC, a Novel and Potential Pharmacodynamic Biomarker for Dasatinib (SPRYCEL), a Multi-Targeted Kinase Inhibitor. Cancer Chemother. Pharmacol. 62, 1065-1074. doi:10.1007/s00280-008-0699-5

Luo, F. R., Yang, Z., Camuso, A., Smykla, R., Mcglinchey, K., Fager, K., et al. (2006a). Dasatinib (BMS-354825) Pharmacokinetics and Pharmacodynamic Biomarkers in Animal Models Predict Optimal Clinical Exposure. Clin. Cancer Res. 12, 7180-7186. doi:10.1158/1078-0432.CCR-06-1112

Luo, F. R., Yang, Z., Camuso, A., Smykla, R., Mcglinchey, K., Fager, K., et al. (2006b). Dasatinib (BMS-354825) Pharmacokinetics and Pharmacodynamic Biomarkers in Animal Models Predict Optimal Clinical Exposure. Clin. Cancer Res. 12, 7180-7186. doi:10.1158/1078-0432.CCR-06-1112
Maher, H. M., Alzoman, N. Z., Shehata, S. M., and Abanmy, N. O. (2018). Validated UPLC-MS/MS Method for the Quantification of Dasatinib in Plasma: Application to Pharmacokinetic Interaction Studies with Nutraceuticals in Wistar Rats. PLoS One 13, e0199208. doi:10.1371/journal.pone.0199208

Matsuoka, A., Takahashi, N., Miura, M., Niioka, T., Kawakami, K., Matsunaga, T., et al. (2012). H2-receptor Antagonist Influences Dasatinib Pharmacokinetics in a Patient with Philadelphia-positive Acute Lymphoblastic Leukemia. Cancer Chemother. Pharmacol. 70, 351-352. doi:10.1007/s00280-012-1900-4

Merienne, C., Rousset, M., Ducint, D., Castaing, N., Titier, K., Molimard, M., et al. (2018). High Throughput Routine Determination of 17 Tyrosine Kinase Inhibitors by LC-MS/MS. J. Pharm. Biomed. Anal. 150, 112-120. doi:10.1016/j.jpba.2017.11.060

Mikus, G., and Foerster, K. I. (2017). Role of CYP3A4 in Kinase Inhibitor Metabolism and Assessment of CYP3A4 Activity. Transl. Cancer Res. 6, S1592-S1599. doi:10.21037/tcr.2017.09.10

Miura, M., and Takahashi, N. (2019). Management Using the Plasma Concentration of Tyrosine Kinase Inhibitors for the Treatment of Chronic Myelogenous Leukemia: an Update. Rinsho Ketsueki 60, 1140-1147. doi:10.11406/rinketsu.60.1140

Miura, M., and Takahashi, N. (2016). Routine Therapeutic Drug Monitoring of Tyrosine Kinase Inhibitors by HPLC-UV or LC-MS/MS Methods. Drug Metab. Pharmacokinet. 31, 12-20. doi:10.1016/j.dmpk.2015.09.002

Mizuta, S., Sawa, M., Tsurumi, H., Matsumoto, K., Miyao, K., Hara, T., et al. (2018). Plasma Concentrations of Dasatinib Have a Clinical Impact on the Frequency of Dasatinib Dose Reduction and Interruption in Chronic Myeloid Leukemia: an Analysis of the DARIA 01 Study. Int. J. Clin. Oncol. 23, 980-988. doi:10.1007/s10147-018-1300-9

Mukai, Y., Yoshida, T., Kondo, T., Inotsume, N., and Toda, T. (2020). Novel HighPerformance Liquid Chromatography-Tandem Mass Spectrometry Method for Simultaneous Quantification of BCR-ABL and Bruton's Tyrosine Kinase Inhibitors and Their Three Active Metabolites in Human Plasma. J. Chromatogr. B Analyt Technol. Biomed. Life Sci. 1137, 121928. doi:10.1016/j.jchromb.2019.121928

Mustjoki, S., Auvinen, K., Kreutzman, A., Rousselot, P., Hernesniemi, S., Melo, T., et al. (2013). Rapid Mobilization of Cytotoxic Lymphocytes Induced by Dasatinib Therapy. Leukemia 27, 914-924. doi:10.1038/leu.2012.348

O'hare, T., Eide, C. A., Agarwal, A., Adrian, L. T., Zabriskie, M. S., Mackenzie, R. J., et al. (2013). Threshold Levels of ABL Tyrosine Kinase Inhibitors Retained in Chronic Myeloid Leukemia Cells Determine Their Commitment to Apoptosis. Cancer Res. 73, 3356-3370. doi:10.1158/0008-5472.CAN-12-3904

Orr, J. M., Abbott, F. S., Farrell, K., Ferguson, S., Sheppard, I., and Godolphin, W. (1982). Interaction between Valproic Acid and Aspirin in Epileptic Children: Serum Protein Binding and Metabolic Effects. Clin. Pharmacol. Ther. 31, 642-649. doi:10.1038/clpt.1982.89

Pape, E., Michel, D., Scala-Bertola, J., Schiestel, T., Harlé, A., Bouchet, S., et al. (2016). Effect of Esomeprazole on the Oral Absorption of Dasatinib in a Patient with Philadelphia-positive Acute Lymphoblastic Leukemia. Br. J. Clin. Pharmacol. 81, 1195-1196. doi:10.1111/bcp.12895

Pauli-Magnus, C., Rekersbrink, S., Klotz, U., and Fromm, M. F. (2001). Interaction of Omeprazole, Lansoprazole and Pantoprazole with P-Glycoprotein. Naunyn Schmiedebergs Arch. Pharmacol. 364, 551-557. doi:10.1007/s00210-001-0489-7

Polli, J. W., Olson, K. L., Chism, J. P., John-Williams, L. S., Yeager, R. L., Woodard, S. M., et al. (2009). An Unexpected Synergist Role of P-Glycoprotein and Breast Cancer Resistance Protein on the central Nervous System Penetration of the Tyrosine Kinase Inhibitor Lapatinib (N-\{3-chloro-4-[(3-fluorobenzyl)oxy] phenyl\}-6-[5-(\{[2-(methylsulfonyl)ethyl]amino\}methyl)-2-furyl $]-4$ quinazolinamine; GW572016). Drug Metab. Dispos 37, 439-442. doi:10.1124/ dmd.108.024646

Porkka, K., Koskenvesa, P., Lundán, T., Rimpiläinen, J., Mustjoki, S., Smykla, R., et al. (2008). Dasatinib Crosses the Blood-Brain Barrier and Is an Efficient Therapy for central Nervous System Philadelphia Chromosome-Positive Leukemia. Blood 112, 1005-1012. doi:10.1182/blood-2008-02-140665

Rousselot, P., Mollica, L., Guilhot, J., Guerci, A., Nicolini, F. E., Etienne, G., et al. (2021). Dasatinib Dose Optimisation Based on Therapeutic Drug Monitoring Reduces Pleural Effusion Rates in Chronic Myeloid Leukaemia Patients. Br. J. Haematol. 194, 393-402. doi:10.1111/bjh.17654

Shah, N. P., Kantarjian, H. M., Kim, D. W., Réa, D., Dorlhiac-Llacer, P. E., Milone, J. H., et al. (2008a). Intermittent Target Inhibition with Dasatinib $100 \mathrm{Mg}$ once 
Daily Preserves Efficacy and Improves Tolerability in Imatinib-Resistant and -Intolerant Chronic-phase Chronic Myeloid Leukemia. J. Clin. Oncol. 26, 3204-3212. doi:10.1200/JCO.2007.14.9260

Shah, N. P., Kasap, C., Weier, C., Balbas, M., Nicoll, J. M., Bleickardt, E., et al. (2008b). Transient Potent BCR-ABL Inhibition Is Sufficient to Commit Chronic Myeloid Leukemia Cells Irreversibly to Apoptosis. Cancer Cell 14, 485-493. doi:10.1016/j.ccr.2008.11.001

Shah, N. P., Kim, D. W., Kantarjian, H., Rousselot, P., Llacer, P. E., Enrico, A., et al. (2010). Potent, Transient Inhibition of BCR-ABL with Dasatinib $100 \mathrm{Mg}$ Daily Achieves Rapid and Durable Cytogenetic Responses and High Transformationfree Survival Rates in Chronic Phase Chronic Myeloid Leukemia Patients with Resistance, Suboptimal Response or Intolerance to Imatinib. Haematologica 95, 232-240. doi:10.3324/haematol.2009.011452

Shah, N. P., Rousselot, P., Schiffer, C., Rea, D., Cortes, J. E., Milone, J., et al. (2016). Dasatinib in Imatinib-Resistant or -intolerant Chronic-phase, Chronic Myeloid Leukemia Patients: 7-year Follow-Up of Study CA180-034. Am. J. Hematol. 91, 869-874. doi:10.1002/ajh.24423

Skoglund, K., Moreno, S. B., Baytar, M., Jönsson, J. I., and Gréen, H. (2013). ABCB1 Haplotypes Do Not Influence Transport or Efficacy of Tyrosine Kinase Inhibitors In Vitro. Pharmgenomics Pers Med. 6, 63-72. doi:10.2147/PGPM.S45522

Snead, J. L., O'hare, T., Adrian, L. T., Eide, C. A., Lange, T., Druker, B. J., et al. (2009). Acute Dasatinib Exposure Commits Bcr-abl-dependent Cells to Apoptosis. Blood 114, 3459-3463. doi:10.1182/blood-2007-10-113969

Sumimoto, T., Nakahara, R., Suzuki, Y., Tanaka, R., Yoshida, N., Ogata, M., et al. (2021). Development of a Sensitive and High-Throughput Assay for Simultaneous Quantification of Five Tyrosine Kinase Inhibitors and Two Active Metabolites in Human Plasma Using Ultra-high Performance Liquid Chromatography Coupled to Tandem Mass Spectrometry. Ther. Drug Monit. doi:10.1097/ftd.0000000000000922

Takahashi, N., Miura, M., Niioka, T., and Sawada, K. (2012a). Influence of H2Receptor Antagonists and Proton Pump Inhibitors on Dasatinib Pharmacokinetics in Japanese Leukemia Patients. Cancer Chemother. Pharmacol. 69, 999-1004. doi:10.1007/s00280-011-1797-3

Takahashi, N., Miura, M., Scott, S. A., Niioka, T., and Sawada, K. (2012b). Pharmacokinetics of Dasatinib for Philadelphia-positive Acute Lymphocytic Leukemia with Acquired T315I Mutation. J. Hematol. Oncol. 5, 23. doi:10.1186/ 1756-8722-5-23

Talpaz, M., Shah, N. P., Kantariian, H., Donato, N., Nicoll, J., Paquette, R., et al. (2006). Dasatinib in Imatinib-Resistant Philadelphia Chromosome-Positive Leukemias. N. Engl. J. Med. 354, 2531-2541. doi:10.1056/NEJMoa055229

Tsume, Y., Takeuchi, S., Matsui, K., Amidon, G. E., and Amidon, G. L. (2015). In Vitro dissolution Methodology, Mini-Gastrointestinal Simulator (mGIS), Predicts Better In Vivo Dissolution of a Weak Base Drug, Dasatinib. Eur. J. Pharm. Sci. 76, 203-212. doi:10.1016/j.ejps.2015.05.013

Uchiyama, T., Sato, N., Narita, M., Yamahira, A., Iwabuchi, M., Furukawa, T., et al. (2013). Direct Effect of Dasatinib on Proliferation and Cytotoxicity of Natural Killer Cells in In Vitro Study. Hematol. Oncol. 31, 156-163. doi:10.1002/hon.2034

Vainstein, V., Eide, C. A., O’Hare, T., Shukron, O., and Druker, B. J. (2013). Integrating In Vitro Sensitivity and Dose-Response Slope Is Predictive of Clinical Response to ABL Kinase Inhibitors in Chronic Myeloid Leukemia. Blood 122, 3331-3334. doi:10.1182/blood-2012-08-452409

Verheijen, R. B., Yu, H., Schellens, J. H. M., Beijnen, J. H., Steeghs, N., and Huitema, A. D. R. (2017). Practical Recommendations for Therapeutic Drug Monitoring of Kinase Inhibitors in Oncology. Clin. Pharmacol. Ther. 102, 765-776. doi:10.1002/cpt.787

Verougstraete, N., Stove, V., Verstraete, A. G., and Stove, C. (2021). Quantification of Eight Hematological Tyrosine Kinase Inhibitors in Both Plasma and Whole Blood by a Validated LC-MS/MS Method. Talanta 226, 122140. doi:10.1016/ j.talanta.2021.122140

Wang, X., Roy, A., Hochhaus, A., Kantarjian, H. M., Chen, T. T., and Shah, N. P. (2013). Differential Effects of Dosing Regimen on the Safety and Efficacy of
Dasatinib: Retrospective Exposure-Response Analysis of a Phase III Study. Clin. Pharmacol. 5, 85-97. doi:10.2147/CPAA.S42796

Wang, X., Hochhaus, A., Kantarjian, H. M., Agrawal, S., Roy, A., Pfister, M., et al. (2008). Dasatinib Pharmacokinetics and Exposure-Response (E-R): Relationship to Safety and Efficacy in Patients (Pts) with Chronic Myeloid Leukemia (CML). J. Clin. Oncol. 26, 3590. doi:10.1200/ jco.2008.26.15_suppl.3590

Weersma, R. K., Zhernakova, A., and Fu, J. (2020). Interaction between Drugs and the Gut Microbiome. Gut 69, 1510-1519. doi:10.1136/gutjnl-2019-320204

Widmer, N., Bardin, C., Chatelut, E., Paci, A., Beijnen, J., Levêque, D., et al. (2014). Review of Therapeutic Drug Monitoring of Anticancer Drugs Part Two Targeted Therapies. Eur. J. Cancer 50, 2020-2036. doi:10.1016/ j.ejca.2014.04.015

Wojnicz, A., Colom-Fernández, B., Steegmann, J. L., Muñoz-Calleja, C., AbadSantos, F., and Ruiz-Nuño, A. (2017). Simultaneous Determination of Imatinib, Dasatinib, and Nilotinib by Liquid Chromatography-Tandem Mass Spectrometry and its Application to Therapeutic Drug Monitoring. Ther. Drug Monit. 39, 252-262. doi:10.1097/FTD.0000000000000406

Yago, M. R., Frymoyer, A., Benet, L. Z., Smelick, G. S., Frassetto, L. A., Ding, X., et al. (2014). The Use of Betaine $\mathrm{HCl}$ to Enhance Dasatinib Absorption in Healthy Volunteers with Rabeprazole-Induced Hypochlorhydria. Aaps $j$ 16, 1358-1365. doi:10.1208/s12248-014-9673-9

Yu, H., Steeghs, N., Nijenhuis, C. M., Schellens, J. H., Beijnen, J. H., and Huitema, A. D. (2014). Practical Guidelines for Therapeutic Drug Monitoring of Anticancer Tyrosine Kinase Inhibitors: Focus on the Pharmacokinetic Targets. Clin. Pharmacokinet. 53, 305-325. doi:10.1007/s40262-014-0137-2

Yu, M., Liu, M., Zhang, W., and Ming, Y. (2018). Pharmacokinetics, Pharmacodynamics and Pharmacogenetics of Tacrolimus in Kidney Transplantation. Curr. Drug Metab. 19, 513-522. doi:10.2174/ 1389200219666180129151948

Zeng, J., Cai, H. L., Jiang, Z. P., Wang, Q., Zhu, Y., Xu, P., et al. (2017). A Validated UPLC-MS/MS Method for Simultaneous Determination of Imatinib, Dasatinib and Nilotinib in Human Plasma. J. Pharm. Anal. 7, 374-380. doi:10.1016/ j.jpha.2017.07.009

Zhang, W., Chang, Y. Z., Kan, Q. C., Zhang, L. R., Li, Z. S., Lu, H., et al. (2010). CYP3A4 ${ }^{*} 1 \mathrm{G}$ Genetic Polymorphism Influences CYP3A Activity and Response to Fentanyl in Chinese Gynecologic Patients. Eur. J. Clin. Pharmacol. 66, 61-66. doi:10.1007/s00228-009-0726-4

Zhou, H. S., Dai, M., Wei, Y., Wang, Q., Xu, N., Yin, C., et al. (2013). Isolated central Nervous System Relapse in Patient with Blast-Crisis Chronic Myeloid Leukemia in Durable Complete Cytogenetic Remission on Dasatinib Treatment: Pharmacokinetics and ABL Mutation Analysis in Cerebrospinal Fluid. Leuk. Lymphoma 54, 1557-1559. doi:10.3109/10428194.2012.745933

Conflict of Interest: The authors declare that the research was conducted in the absence of any commercial or financial relationships that could be construed as a potential conflict of interest.

Publisher's Note: All claims expressed in this article are solely those of the authors and do not necessarily represent those of their affiliated organizations, or those of the publisher, the editors, and the reviewers. Any product that may be evaluated in this article, or claim that may be made by its manufacturer, is not guaranteed or endorsed by the publisher.

Copyright $\odot 2021$ He, Bian, Shao, Zhang, Hao, Luo, Feng and Huang. This is an open-access article distributed under the terms of the Creative Commons Attribution License (CC BY). The use, distribution or reproduction in other forums is permitted, provided the original author(s) and the copyright owner(s) are credited and that the original publication in this journal is cited, in accordance with accepted academic practice. No use, distribution or reproduction is permitted which does not comply with these terms. 